\title{
Effectiveness of face masks in blocking the transmission of SARS-CoV-2: A preliminary evaluation of masks used by SARS-CoV-2- infected individuals
}

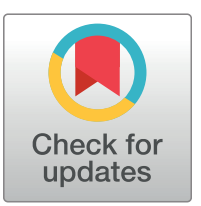

\section{fopen access}

Citation: Mello VM, Eller CM, Salvio AL, Nascimento FF, Figueiredo CM, Silva ESRF, et al. (2022) Effectiveness of face masks in blocking the transmission of SARS-CoV-2: A preliminary evaluation of masks used by SARS-CoV-2-infected individuals. PLoS ONE 17(2): e0264389. https:// doi.org/10.1371/journal.pone.0264389

Editor: Amitava Mukherjee, VIT University, INDIA

Received: July 6, 2021

Accepted: February 9, 2022

Published: February 23, 2022

Copyright: ๑ 2022 Mello et al. This is an open access article distributed under the terms of the Creative Commons Attribution License, which permits unrestricted use, distribution, and reproduction in any medium, provided the original author and source are credited.

Data Availability Statement: All relevant data are within the manuscript. More data available on request due to privacy/ethical restrictions (contact via etica@fiocruz.br or +55 21 3882-9011), for researchers who meet the criteria for access to confidential data.

Funding: This study was funded by: The Fiocruz Promote Innovation Program, "Inova Fiocruz", through Oswaldo Cruz Foundation and Science, Technology and Strategic Inputs Secretariat of Brazilian Ministry of Health. (ERSL and MAPH).

\author{
Vinicius M. Mello ${ }^{1 \oplus \neq *}$, Cristiane M. Eller ${ }^{2 \oplus \neq}$, Andreza L. Salvio ${ }^{3 \oplus \neq}$, Felipe F. Nascimento ${ }^{3}$, \\ Camila M. Figueiredo ${ }^{3}$, Emanuelle S. R. F. Silva ${ }^{3}$, Paulo S. F. Sousa ${ }^{1}$, Pamela F. Costa ${ }^{3}$, \\ Anne A. P. Paiva ${ }^{4}$, Maria A. M. M. Mares-Guias ${ }^{4}$, Elba R. S. Lemos ${ }^{5}$, Marco A. P. Horta ${ }^{2 \odot}$ \\ 1 Viral Hepatitis Laboratory, Oswaldo Cruz Institute, Oswaldo Cruz Foundation, Rio de Janeiro, Brazil, \\ 2 Biosafety Level 3 Facility (BSL-3), Oswaldo Cruz Foundation, Rio de Janeiro, Brazil, 3 COVID-19 \\ Analytical Center, Oswaldo Cruz Foundation, Rio de Janeiro, Brazil, 4 Flavivirus Laboratory, Oswaldo Cruz \\ Institute, Oswaldo Cruz Foundation, Rio de Janeiro, Brazil, 5 Hantavirosis and Rickettsiosis Laboratory, \\ Oswaldo Cruz Institute, Oswaldo Cruz Foundation, Rio de Janeiro, Brazil \\ ه These authors contributed equally to this work. \\ ¥ VMM, CME and ALS share first authorship on this work. \\ *vmello.fiocruz@gmail.com
}

\section{Abstract}

In 2019, a novel severe acute respiratory syndrome coronavirus 2 (SARS-CoV-2), which is transmitted via the airborne route, caused a new pandemic namely, "coronavirus disease 2019" (COVID-19). Although the effectiveness of face masks to prevent the transmission of SARS-CoV-2 is debated, no study has evaluated the virus-blocking efficacy of masks used by patients. We aimed to evaluate this efficacy of masks used by SARS-CoV-2-infected individuals. Data, masks used, and nasopharyngeal swab samples were obtained from these patients. Forty-five paired samples of nasopharyngeal swabs and masks were obtained and processed; the majority of masks were woven. Viral RNAs were amplified using quantitative reverse-transcription polymerase chain reaction and detected only on the inner parts of masks. Median viral load (VL) values of swabs and masks were $1.954 \times 10^{6}$ and $2,51 \times 10^{3}$, respectively. Statistically, there was a difference of approximately 1000 RNA copies $/ \mathrm{mL}$ between swabs and masks and no significant difference in VL values among different types of masks. There were statistically significant differences in VL values between men and women and between symptomatic and asymptomatic patients. Our findings suggest the blocking of virus transmission by different types of masks and reinforce the use of masks by both infected and non-infected individuals.

\section{Introduction}

In 2019, a new respiratory coronavirus named, severe acute respiratory syndrome coronavirus 2 (SARS-CoV-2), which is transmitted via the airborne route, primarily through respiratory 
https://portal.fiocruz.br/inova And funded by the Brazilian national funding agency "Coordenação de Aperfeiçoamento de Pessoal de Nível Superior do Brasil-CAPES", under finance code 001. (VMM and AAPV) https://www.gov.br/capes/pt-br The funders had no role in the design of the study; in the collection, analyses, or interpretation of data; in the writing of the manuscript, or in the decision to publish the results.

Competing interests: The authors have declared that no competing interests exist. droplets and aerosols, caused the new global pandemic. This new virus was associated with a respiratory syndrome denominated as "coronavirus disease 2019" (COVID-19) that has resulted in millions of deaths $[1,2]$. Some studies suggest that the use of a mask can potentially prevent the transmission of several respiratory viruses, such as influenza and rhinovirus, in addition to the new coronavirus [3-5]. Although there has been much discussion regarding whether masks should be used to prevent viral transmission during the initial period of the COVID-19 pandemic, there is now a global understanding of the importance of using masks for preventing SARS-CoV-2 infection. It has been reported that masks not only protect the person who is wearing it, but also reduce the likelihood of disease transmission from the person wearing the mask to another person [6].

Current epidemiological data indicate that wearing a mask can reduce the emission of SARS-CoV-2 particles into the environment [7]. The surgical mask (non-woven mask) had a greater filtration efficiency for viral aerosols; however, the filtration efficiency was inferior to that of an N95 mask [8-11]. With the worsening of the pandemic in some countries, especially the developing ones, countries have suffered from the non-availability of surgical masks $[8,12$, 13]. As a great alternative, homemade fabric masks have become very popular in several affected countries, mainly in Brazil [14-20]. Although fabric masks provide less protection and have a low filtering efficiency when compared with surgical masks, they may have some effectiveness in preventing the transmission of SARS-CoV-2 [8-11]. Nevertheless, these homemade masks are produced by small-scale fashion productions and do not have quality certifications from health authorities [14-20].

Despite the World Health Organization recommendations about the use of face masks, whether it reduces the risk of transmission of SARS-CoV-2 is still controversial [21]. Few or no studies evaluated the presence of retained viruses on the masks of different materials, as well as the effectiveness of these masks in preventing viral transmission. Considering the heterogeneity of cloth masks that are sold in Brazil, it is still unclear whether these homemade masks are effective in blocking the transmission of the virus. Considering these points, in the present study, we aimed to evaluate the virus-blocking efficacy of masks used by SARS-CoV2 -infected individuals.

The results presented here suggest that the use of masks helps to block viral trans-mission by SARS-CoV-2-infected individuals and reinforce the importance of using masks as a preventive measure against the viral transmission.

\section{Materials and methods}

\subsection{Ethics statement}

The Oswaldo Cruz Institute/IOC/FIOCRUZ Research Ethics Committee approved this study (number: CAAE 37142520.0.0000.5248). All procedures were performed in accordance with the ethical standards of the responsible committees on human experimentation (institutional and national) and the Helsinki Declaration of 1975, as revised in 2008. All patients who were included in the study agreed to their participation in the research by signing the informed consent form.

\subsection{Study population and sample collection}

Nasopharyngeal swab samples and masks were collected (between December 2020 to March 2021) from patients who were suspected to be infected by SARS-CoV-2 and attended the Municipal Theatre and Benjamin Constant Institute survey, conducted in the city of Rio de Janeiro, Brazil, according to medical decision and after obtaining permissions from the patients. 
Samples were collected as follows: a nasopharyngeal swab was inserted in the nostril until it hit an obstacle (the inferior concha or the back of the nasopharyngeal cavity), rotated, and removed. The test was conducted in two nostrils per patient. After sampling, the nasopharyngeal swab was inserted into a vial containing $3 \mathrm{~mL}$ of a viral transport medium (VTM; Xpert nasopharyngeal sample collection kit, Cepheid, Sunnyvale, CA, USA). After the collection of swab samples, the masks used for $2-3 \mathrm{~h}$ by the participants were placed inside a clean plastic bag and they were provided clean, new masks for use. Furthermore, data, including the biological sex and age of these patients were collected.

\subsection{Processing of masks and swabs}

The nasopharyngeal swab specimen was collected and immediately resuspended in $3 \mathrm{~mL}$ of the VTM. For mask samples, immediately after the collection of masks, pieces were cut based on the following reference measures: the right side and left side areas with a width of $2 \mathrm{~cm}$ each, obtained after removing side seam using the entire height of the mask; the nose area $(\mathrm{N})$ with a height of $5 \mathrm{~cm}$ and width of $5 \mathrm{~cm}$; and the mouth area (M) with a height of $5 \mathrm{~cm}$ and width of $8 \mathrm{~cm}$, and subsequently, these pieces were added to the VTM. In cases of samples with double or triple layers of the material, these areas were subdivided into inner part of $\mathrm{N}$, middle part of $\mathrm{N}$, outer part of $\mathrm{N}$, inner part of $\mathrm{M}$, middle part of $\mathrm{M}$, and outside part of $\mathrm{M}$, respecting the sizes of the cut areas previously described (Fig 1 ). The parts with the lowest CT among the four main parts of the masks (mouth, nose, left side and right side) were selected for analysis, the table presents only this result. At this first moment, we hadn't analyzed the middle layer (this layer is located between the inner and outer layers in non-woven masks that have three layers of protection).

Between resuspension and the processing of each sample (swabs and mask pieces), incubation at $4^{\circ} \mathrm{C}$ for a minimum of 30 minutes and a maximum of 12 hours was be performed. Subsequently, the samples were processed through vortex homogenization and transferred from the medium to a previously identified $1.5-\mathrm{mL}$ tube using a Pasteur pipette $(2 \mathrm{~mL})$. Then, swabs and masks were discarded, and the final sample in the medium was stored at $-80^{\circ} \mathrm{C}$.

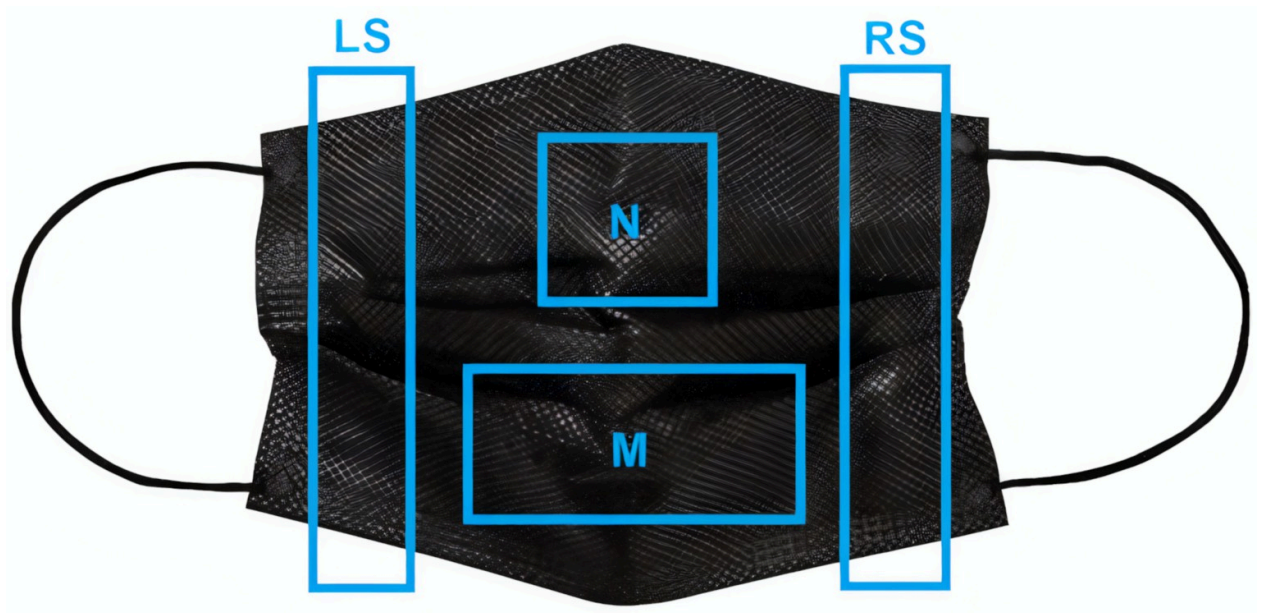

Fig 1. The scheme for cutting a mask. The areas enclosed within blue margins represent the areas cut from the mask. LS = Left Side, RS = Right Side, $\mathrm{M}=$ Mouth area, and $\mathrm{N}=$ Nose area.

https://doi.org/10.1371/journal.pone.0264389.g001 


\subsection{Viral genome extraction}

Nucleic acid from all the samples was extracted and purified using the DNA/RNA 300 kit H96 in the Janus G3 and Janus Chemagic automatic extractor (Perkin-Elmer, Waltham, USA). The Janus 360 system is based on magnetic spheres for extracting viral nucleic acids from $300 \mathrm{uL}$ of the sample. The operation of the equipment and the use of the commercial kit were in accordance with the manufacturer's instructions.

\subsection{SARS-CoV-2 molecular detection}

For SARS-CoV-2 genome amplification, we used a molecular kit for the E region (Bio-Manguinhos, Rio de Janeiro, BR) following the manufacturer's instructions. The plate setup was automated and performed using Janus G3 (Perkin-Elmer, Waltham, USA). In this method, the quantitative reverse-transcription polymerase chain reaction (qRT-PCR) also allowed the quantification of viral genomic RNA of SARS-CoV-2 with the application of an in-house ssRNA standard curve. The chosen commercial kit helped in detecting the $\mathrm{E}$ region of the genome using a FAM probe and the RP human gene using a VIC probe; the latter functions as the internal positive control of the assay. For all assays, positive and negative controls were included in the commercial molecular kit, and they were used in all experiments.

Samples with a cycle threshold (Ct) value lower than 38.0 for E region were considered positive, and negative samples were the ones that presented a Ct value higher than 38.0 or no Ct value at all. For the RP target, a Ct value equal to or lower than 35.0 validated the experiment. The positive control Ct value must be lower than 37.0 to validate the assay. All samples that that presented a higher cycle threshold (CT \pm 38 ) and that had viral load, had the qPCR repeated for confirmation, those which had detectable RNA copies in both analyses were considered positive.

\subsection{Statistical analysis}

The results of descriptive statistical analyses are presented using frequency tabulations and percentages. Medians are presented with interquartile range (IQR) values. The Mann-Whitney $U$ test was used to compare the differences in viral loads between the independent groups of masks and swabs. Statistical significance was set at a p-value $\leq 0.05$. All analyses were performed using R software version 4.1.0 (The R Foundation for Statistical Computing, Vienna, Austria).

\section{Results}

Forty-five swab samples with their paired respective masks were collected. The masks were classified as woven masks $(30 / 45 ; 66.7 \%)$ and surgical non-woven masks $(15 / 45,33.3 \%)$. SARS-CoV-2 RNA was detected in all swab samples and 24/45 (53,3\%) inner part of the masks (CTs $<38$ ). One/24 mask with $\mathrm{Ct}>38$ ( $\mathrm{Ct} 38.02$ ) was considered positive after having the qPCR repeated for confirmation, having a detectable viral load of $2.39 \times 10^{3}$ copies $/ \mathrm{mL}$. The viral RNA was detected only on the inner part (the part that was in contact with the face) of the masks. None of the masks was positive for the RNA on the outer part (the part that was in contact with the external environment). Through qPCR, we observed that 7/24 (29,1\%) masks had positive CT in the left and right sides, these CTs were all above 25, ranging from 25 to 38 . The median viral load values of the swab and mask samples were $1.954 \times 10^{6}$ (IQR, 1.91 $\times 10^{5}$ $2.34 \times 10^{8}$ ) and $2,51 \times 10^{3}$ (IQR, $0.0-2,51 \times 10^{3}$ ), respectively. The descriptive information can be seen in Table 1. 
Table 1. Epidemiological characteristics of patients infected with SARS-CoV-2 in the present study.

\begin{tabular}{|c|c|c|c|c|c|c|c|c|}
\hline Sample & Age Range & Sex & Swab Ct & Swab VL & Mask Ct & Mask VL & Material & Symptoms \\
\hline 1 & 20 to 29 years & Male & 23.97 & $4.33 \times 10^{7}$ & 36.65 & $6.21 \times 10^{3}$ & Surgical & Yes \\
\hline 2 & 20 to 29 years & Male & 31.47 & $2.30 \times 10^{5}$ & 37.95 & $2.51 \times 10^{3}$ & Surgical & Yes \\
\hline 3 & 20 to 29 years & Male & 34.18 & $3.48 \times 10^{4}$ & 38.02 & $2.39 \times 10^{3}$ & Surgical & Yes \\
\hline 4 & 20 to 29 years & Male & 31.43 & $2.37 \times 10^{5}$ & 40.0 & 0 & Surgical & Yes \\
\hline 5 & 40 to 49 years & Male & 20.34 & $5.46 \times 10^{8}$ & 26.52 & $7.31 \times 10^{6}$ & Woven & No \\
\hline 6 & 60 to 69 years & Female & 20.75 & $4.10 \times 10^{8}$ & 24.6 & $2.79 \times 10^{7}$ & Woven & Yes \\
\hline 7 & 60 to 69 years & Male & 32.81 & $9.06 \times 10^{4}$ & 40.0 & 0 & Woven & No \\
\hline 8 & 40 to 49 years & Male & 35.79 & $1.13 \times 10^{4}$ & 40.0 & 0 & Woven & Yes \\
\hline 9 & 40 to 49 years & Male & 16.17 & $1.00 \times 10^{10}$ & 30.59 & $4.27 \times 10^{5}$ & Woven & Yes \\
\hline 10 & 20 to 29 years & Female & 24.48 & $3.03 \times 10^{7}$ & 34.74 & $2.36 \times 10^{4}$ & Woven & Yes \\
\hline 11 & 30 to 39 years & Male & 30.26 & $5.37 \times 10^{5}$ & 40.0 & 0 & Woven & Yes \\
\hline 12 & 60 to 69 years & Male & 28.06 & $2.49 \times 10^{6}$ & 40.0 & 0 & Surgical & Yes \\
\hline 13 & 30 to 39 years & Female & 21.34 & $2.71 \times 10^{8}$ & 28.99 & $1.30 \times 10^{6}$ & Woven & Yes \\
\hline 14 & 60 to 69 years & Female & 31.05 & $3.09 \times 10^{5}$ & 40.0 & 0 & Woven & No \\
\hline 15 & 40 to 49 years & Female & 20.11 & $6.41 \times 10^{8}$ & 34.08 & $3.73 \times 10^{4}$ & Woven & Yes \\
\hline 16 & 40 to 49 years & Female & 32.6 & $1.04 \times 10^{5}$ & 35.18 & $1.73 \times 10^{4}$ & Woven & Yes \\
\hline 17 & 60 to 69 years & Female & 16.0 & $1.12 \times 10^{10}$ & 25.11 & $1.96 \times 10^{7}$ & Woven & Yes \\
\hline 18 & 20 to 29 years & Male & 21.55 & $2.34 \times 10^{8}$ & 37.71 & $2.96 \times 10^{3}$ & Surgical & Yes \\
\hline 19 & 60 to 69 years & Male & 15.49 & $1.61 \times 10^{10}$ & 40.0 & 0 & Woven & No \\
\hline 20 & 20 to 29 years & Female & 16.07 & $1.07 \times 10^{10}$ & 28.9 & $1.39 \times 10^{6}$ & Woven & Yes \\
\hline 21 & 30 to 39 years & Male & 20.54 & $4.74 \times 10^{8}$ & 33.5 & $5.60 \times 10^{4}$ & Woven & Yes \\
\hline 22 & 70 years or more & Male & 33.84 & $4.41 \times 10^{4}$ & 40.0 & 0 & Woven & No \\
\hline 23 & 40 to 49 years & Male & 34.9 & $2.10 \times 10^{4}$ & 40.0 & 0 & Woven & No \\
\hline 24 & 50 to 59 years & Female & 24.87 & $2.31 \times 10^{7}$ & 40.0 & 0 & Woven & Yes \\
\hline 25 & 50 to 59 years & Female & 24.87 & $2.31 \times 10^{7}$ & 40.0 & 0 & Woven & Yes \\
\hline 26 & 50 to 59 years & Female & 24.87 & $2.31 \times 10^{7}$ & 24.05 & $4.10 \times 10^{7}$ & Woven & Yes \\
\hline 27 & 50 to 59 years & Male & 31.74 & $1.91 \times 10^{5}$ & 40.0 & 0 & Woven & Yes \\
\hline 28 & 50 to 59 years & Male & 31.74 & $1.91 \times 10^{5}$ & 36.58 & $6.52 \times 10^{3}$ & Woven & Yes \\
\hline 29 & 50 to 59 years & Male & 31.74 & $1.91 \times 10^{5}$ & 37.06 & $4.66 \times 10^{3}$ & Woven & Yes \\
\hline 30 & 20 to 29 years & Female & 15.13 & $2.07 \times 10^{10}$ & 25.61 & $1.38 \times 10^{7}$ & Surgical & Yes \\
\hline 31 & 50 to 59 years & Male & 37.37 & $3.75 \times 10^{3}$ & 40.0 & 0 & Woven & No \\
\hline 32 & 50 to 59 years & Female & 35.29 & $1.60 \times 10^{4}$ & 40.0 & 0 & Woven & Yes \\
\hline 33 & 50 to 59 years & Female & 37.28 & $4.00 \times 10^{3}$ & 40.0 & 0 & Woven & No \\
\hline 34 & 30 to 39 years & Male & 30.52 & $4.48 \times 10^{5}$ & 40.0 & 0 & Surgical & Yes \\
\hline 35 & 30 to 39 years & Female & 28.41 & $1.95 \times 10^{6}$ & 34.34 & $3.11 \times 10^{4}$ & Surgical & Yes \\
\hline 36 & 50 to 59 years & Female & 24.87 & $2.31 \times 10^{7}$ & 29.65 & $8.22 \times 10^{5}$ & Woven & Yes \\
\hline 37 & 20 to 29 years & Female & 28.58 & $1.73 \times 10^{6}$ & 40.0 & 0 & Surgical & Yes \\
\hline 38 & 40 to 49 years & Male & 23.79 & $4.91 \times 10^{7}$ & 31.13 & $2.93 \times 10^{5}$ & Woven & No \\
\hline 39 & 60 to 69 years & Male & 32.84 & $8.87 \times 10^{4}$ & 40.0 & 0 & Surgical & No \\
\hline 40 & 20 to 29 years & Female & 28.04 & $2.52 \times 10^{6}$ & 40.0 & 0 & Surgical & Yes \\
\hline 41 & 30 to 39 years & Male & 31.72 & $1.93 \times 10^{5}$ & 40.0 & 0 & Surgical & No \\
\hline 42 & 30 to 39 years & Male & 30.7 & $3.95 \times 10^{5}$ & 37.46 & $3.53 \times 10^{3}$ & Surgical & No \\
\hline 43 & 50 to 59 years & Male & 36.78 & $5.67 \times 10^{3}$ & 40.0 & 0 & Surgical & No \\
\hline 44 & 30 to 39 years & Female & 24.17 & $3.76 \times 10^{7}$ & 35.44 & $1.45 \times 10^{4}$ & Woven & Yes \\
\hline 45 & 30 to 39 years & Female & 14.39 & $3.47 \times 10^{10}$ & 29.93 & $6.76 \times 10^{5}$ & Woven & Yes \\
\hline
\end{tabular}

$\mathrm{Ct}=$ cycle threshold $\mathrm{VL}=$ Viral Load $($ copies $/ \mathrm{mL})$. 


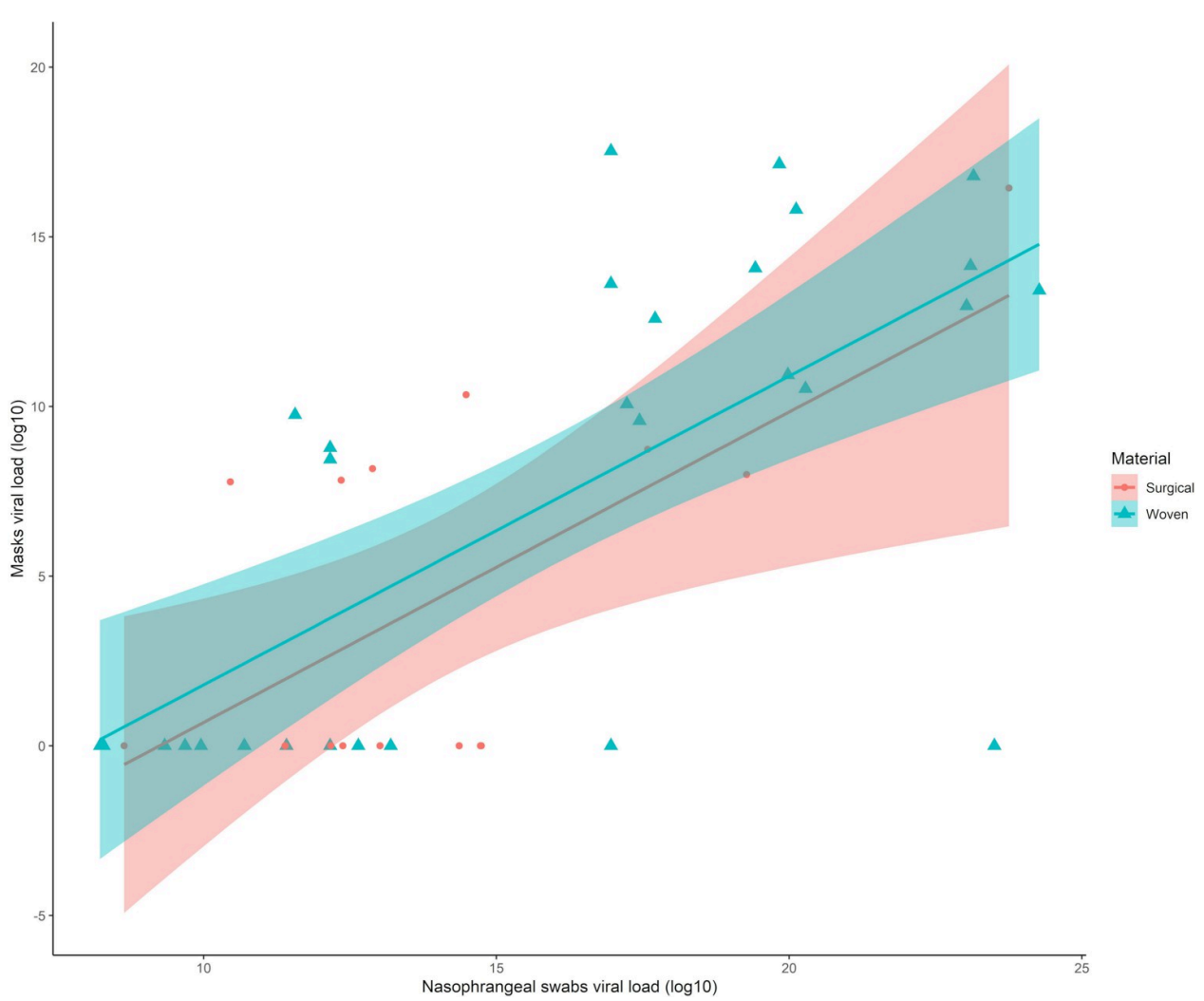

Fig 2. Relationship between severe acute respiratory syndrome coronavirus 2 viral loads of nasopharyngeal swabs and masks used by infected patients.

https://doi.org/10.1371/journal.pone.0264389.g002

Our analysis showed a reduction of approximately $\cong 3$ logs or $1000 \mathrm{RNA}$ copies $/ \mathrm{mL}(\cong 10$ Ct values) between swab and mask samples. Statistical analysis, considering the adjusted linear equation showed a relationship in the reduction of viral load of nasopharyngeal swabs and masks $(\mathrm{Y}=-7.99+0.93 \mathrm{X})$ with a positive and significant correlation $(\mathrm{rho}=0.67, p<0.001)$ (Fig 2).

The analysis did not identify a statistically significant difference in median viral load values between surgical and cloth masks $(\mathrm{U}=163, p=0.11)$. The same result was obtained when comparing $\mathrm{Ct}$ values of nasopharyngeal swabs $(\mathrm{U}=190, p=0.40)$. Viral load was significantly higher in men than in women for masks $(\mathrm{U}=350, p=0.01)$ and swabs $(\mathrm{U}=349, p=0.02)$. We observed viral load values were significantly higher in asymptomatic than in symptomatic patients $(\mathrm{U}=149, p=0.03)$. Further results of statistical analysis can be found in Table 2.

\section{Discussion}

One year after the COVID-19 pandemic, the Americas have become the epicenter of COVID-19 cases and deaths, especially in Brazil, there has been an increase in the average number of deaths [1]. This may be associated with late interventions against the pandemic and adherence to scientific negationism, for example, not wearing protective masks, among other factors [22, 23].

The results of this study reinforce the evidence that in general, wearing masks can be beneficial to the community and that this beneficial effect is derived from the ability of masks to block the exhalation and inhalation of infectious viruses, regardless of the type of mask used, as shown in a review by Brooks and Butler (2021) [24]. 
Table 2. Median viral load values of masks and nasopharyngeal swabs from 45 patients infected by SARS-CoV-2.

\begin{tabular}{|c|c|c|c|c|c|c|c|}
\hline & N (\%) & Masks VL & IQR & P-value & Swab VL & IQR & P-value \\
\hline Sex & & & & 0.01 & & & 0.02 \\
\hline Female & $20(44.4)$ & $2.73 \times 10^{4}$ & $\left(0.0-1.32 \times 10^{6}\right)$ & & $2.31 \times 10^{7}$ & $\left(1.89 \times 10^{6}-4.67 \times 10^{8}\right)$ & \\
\hline Male & $25(55.6)$ & 0.0 & $\left(0.0-4.66 \times 10^{3}\right)$ & & $2.30 \times 10^{5}$ & $\left(8.87 \times 10^{4}-4.33 \times 10^{7}\right)$ & \\
\hline Mask type & & & & 0.11 & & & 0.40 \\
\hline Surgical & $15(33.3)$ & 0.0 & $\left(0.0-3.24 \times 10^{3}\right)$ & & $4.48 \times 10^{5}$ & $\left(2.12 \times 10^{5}-2.51 \times 10^{6}\right)$ & \\
\hline Woven & $30(66.7)$ & $1.05 \times 10^{4}$ & $\left(6.13 \times 10^{5}-4.10 \times 10^{7}\right)$ & & $2.31 \times 10^{7}$ & $\left(1.26 \times 10^{5}-4.58 \times 10^{8}\right)$ & \\
\hline Symptoms & & & & 0.03 & & & 0.01 \\
\hline Yes & $32(71.1)$ & $6.21 \times 10^{3}$ & $\left(0.0-6.97 \times 10^{3}\right)$ & & $2.31 \times 10^{7}$ & $\left(4.48 \times 10^{5}-2.71 \times 10^{8}\right)$ & \\
\hline No & $13(28.9)$ & 0.0 & $\left(0.0-6.76 \times 10^{5}\right)$ & & $9.77 \times 10^{4}$ & $\left(1.86 \times 10^{4}-1.25 \times 10^{7}\right)$ & \\
\hline
\end{tabular}

$\mathrm{IQR}=$ Interquartile range; $\mathrm{VL}=$ Viral Load (copies $/ \mathrm{mL})$.

https://doi.org/10.1371/journal.pone.0264389.t002

Data from different studies conducted in several countries have shown that the use of masks together with social distancing can reduce the transmission of SARS-CoV-2 and the number of cases of SARS-CoV-2 infection [11, 25-28]. A study performed by Ma et al (2020), which used an automated system that mimicked human breathing, showed that the virusblocking rates of surgical and homemade masks were approximately $97 \%$ and $95 \%$. Respectively [29]. Another study performed by Morais et al (2021), which used a similar methodology for evaluating different mask types, demonstrated similar results, where surgical masks had a filtration rate of $89 \%$ and homemade masks had filtration rates ranging from $40 \%$ to $83 \%$, depending on the type of the fabric [30]. Although these studies show promising results, it should be noted, that in both cases the masks were sealed to the test apparatus and that the studies therefore did not include the effects of aerosol leakage through face seal leaks (gaps between the mask and the face), which can occur in a real clinical setting.

In contrast to other studies, Lindsley and colleagues (2021), in addition to evaluating the masks in an automated system, also evaluated the fit of the ones to the face of individuals. Despite presenting similar results to the others, regarding filtering and blocking, it was observed that these factors can be affected when related the fit of the masks to the face of the individual is taken into consideration [31]. The hypothesis of facial fit and incorrect handling of the mask may possibly answer and be related to the fact that some masks $(7 / 24,29.1 \%)$ in our study presented positive inner sides.

In the present study we observed a reduction by approximately $\cong 3$ logs or $\cong 1000$ RNA copies/mL (10 Ct values) for masks compared with the paired swabs collected from the same individual. These findings corroborate with data from the previous studies [29, 30, 32] that indicate a possible blocking of viral transmission by masks worn by infected people; these results may shed light on the effectiveness of masks in blocking SARS-CoV-2.

Another result that reinforced the hypothesis of blocking of viral transmission by masks was that only inner parts (the parts in contact with the face) of the masks were positive for viral RNA. Furthermore, the reduction in viral load of nasopharyngeal swabs and masks showed a significant statistical association ( $r h o=0.67, p<0.001$ ), showing that the virus-blocking rate is possibly relevant in preventing the transmission of the virus from infected people to other individuals, corroborating the results found in the literature [24].

It is important to highlight that a reduction in viral load was observed in the different types of masks (non-woven and woven masks) analyzed, upon comparing swab samples and masks, which were collected simultaneously. Additionally, there was no statistically significant difference in the decrease in viral load among the different types of masks. These results reveal that 
different types of masks may be used to reduce the transmission of viruses to the environment and prevent infection in susceptible individuals. A similar result was obtained in a study performed by Zangmeister et al (2020) that evaluated the effectiveness of the materials of cloth masks, which were used to reduce the transmission of SARS-CoV-2, in the filtration of nanoscale aerosols and showed that and found that cloth masks did not perform similar to an N95 mask. However, woven and non-woven cloth masks may be used to reduce the transmission of SARS-CoV-2 and to filter viral particles [33].

In this context, in a country like Brazil, where it is impossible to totally adopt measures of social distancing, mainly in socially vulnerable populations in peripheral areas and slums, the use of masks seems essential. Moreover, the use of masks could be beneficial to those individuals who still need to use public transport, such as buses, trains, and/or subways, which are often crowded [21,34-36]. The use of masks, especially woven ones, is extremely relevant as an additional protective measure for reducing the increasing number of cases and deaths due to COVID-19 in Brazil [12].

Statistically significant results were obtained on comparing viral load for swabs and masks $(\mathrm{p}=0.01$ and $\mathrm{p}=0.02$, respectively) between men and women. This may be directly associated with the sex a hypothesis to be considered is a greater release of viral particles by males. Some studies have shown that males have a significantly high risk of severe disease, mainly due to differences in inflammatory responses to viral infections. and genetic and hormonal regulation [37-39]. However, more studies are needed to understand the underlying biological phenomena.

Some studies suggest that the viral load found in asymptomatic patients is similar to that found in symptomatic patients [40-42]. However, we identified lower Cts values in symptomatic patients than those in asymptomatic patients, and this difference was statistically significant $(p=0.01)$, indicating an elevated viral load mainly in swab samples (Table 2).

This was a preliminary study and has some limitations. The sample size was relatively small, and this study did not evaluate the filtering efficiency of the masks as performed in some other studies $[28,29]$. Additionally, it was not yet possible to assess the number of viral particles retained and recovered from the masks, nor the consistency of the extraction methodology. However, we recognize that these experiments would be difficult to carry out in a clinical setting. Furthermore, this study only evaluated masks from SARS-CoV-2 infected individuals with a positive qRT-PCRA. Further studies are needed to evaluate the masks of uninfected individuals who have had direct contact with infected individuals. Further studies. including a larger number of masks, are also needed to analyze the viability of the virus detected in infected masks through cell culture.

Nevertheless, our results provided real-life evidence regarding blocking of viral transmission by masks used by individuals infected by SARS-CoV-2. Furthermore, the results also reinforce the suggestion to use a mask by everyone, regardless of whether the individual is infected or not. This is important since there are asymptomatic cases of infection and evidence of virus transmission even before the appearance of the first symptoms [40, 43].

\section{Conclusions}

The study results shed light on the importance of using masks by individuals infected with SARS-CoV-2 and show that different types of masks can help block viral transmission. Moreover, our findings also reinforce the importance of using masks as a preventive measure against the viral transmission, regardless of the type of mask used, in addition to social distancing and personal hygiene measures. 


\section{Acknowledgments}

We are also grateful to the Rio de Janeiro Municipal Theatre team and Benjamin Constant Institute team for our collaboration. We especially thank everyone who made themselves available to participate in this study through the swab and mask collections.

\section{Author Contributions}

Conceptualization: Vinicius M. Mello, Andreza L. Salvio, Elba R. S. Lemos, Marco A. P. Horta.

Data curation: Elba R. S. Lemos, Marco A. P. Horta.

Formal analysis: Marco A. P. Horta.

Funding acquisition: Elba R. S. Lemos, Marco A. P. Horta.

Investigation: Cristiane M. Eller, Andreza L. Salvio, Anne A. P. Paiva, Elba R. S. Lemos, Marco A. P. Horta.

Methodology: Cristiane M. Eller, Andreza L. Salvio, Felipe F. Nascimento, Camila M. Figueiredo, Emanuelle S. R. F. Silva, Paulo S. F. Sousa, Pamela F. Costa, Anne A. P. Paiva, Maria A. M. M. Mares-Guias.

Project administration: Elba R. S. Lemos, Marco A. P. Horta.

Resources: Vinicius M. Mello, Anne A. P. Paiva.

Supervision: Elba R. S. Lemos, Marco A. P. Horta.

Validation: Cristiane M. Eller, Andreza L. Salvio, Felipe F. Nascimento, Marco A. P. Horta.

Visualization: Marco A. P. Horta.

Writing - original draft: Vinicius M. Mello, Andreza L. Salvio, Marco A. P. Horta.

Writing - review \& editing: Vinicius M. Mello, Cristiane M. Eller, Andreza L. Salvio, Elba R. S. Lemos, Marco A. P. Horta.

\section{References}

1. World Health Organization. WHO Coronavirus (COVID-19) Dashboard 2021. https://covid19. who.int. Accessed March 31. 2020.

2. Harrison AG, Lin T, Wang P. Mechanisms of SARS-CoV-2 Transmission and Pathogenesis. Trends Immunol. 2020; 41(12):1100-15. https://doi.org/10.1016/j.it.2020.10.004 PMID: 33132005

3. Leung NHL, Chu DKW, Shiu EYC, et al. Respiratory virus shedding in exhaled breath and efficacy of face masks. Nat Med. 2020; 26(5):676-680. https://doi.org/10.1038/s41591-020-0843-2 PMID: 32371934

4. Milton DK, Fabian MP, Cowling BJ, et al. Influenza virus aerosols in human exhaled breath: particle size. culturability. and effect of surgical masks. PLoS Pathog. 2013; 9(3):e1003205. https://doi.org/10. 1371/journal.ppat.1003205 PMID: 23505369

5. Prather KA, Wang CC, Schooley RT. Reducing transmission of SARS-CoV-2. Science. 2020; 368 (6498):1422-4. https://doi.org/10.1126/science.abc6197 PMID: 32461212

6. Swain ID. Why the mask? The effectiveness of face masks in preventing the spread of respiratory infections such as COVID-19-a home testing protocol. J Med Eng Technol. 2020; 44(6):334-7. https://doi. org/10.1080/03091902.2020.1797198 PMID: 32716230

7. Střížová Z, Bartůňková J, Smrž D. Can wearing face masks in public affect transmission route and viral load in COVID-19? Cent Eur J Public Health. 2020; 28(2):161-2. https://doi.org/10.21101/cejph.a6290 PMID: 32592550

8. World Health Organization. Mask use in the context of COVID-19, 2020. https://apps.who.int/iris/ handle/10665/337199. Accessed April 5. 2020. 
9. Guan L, Zhou L, Zhang J, et al. More awareness is needed for severe acute respiratory syndrome coronavirus 2019 transmission through exhaled air during non-invasive respiratory support: experience from China. Eur Respir J. 2020; 55(3). https://doi.org/10.1183/13993003.00352-2020 PMID: 32198275

10. Remuzzi A, Remuzzi G. COVID-19 and Italy: what next? Lancet. 2020; 395(10231):1225-8. https://doi. org/10.1016/S0140-6736(20)30627-9 PMID: 32178769

11. Choi S, Ki M. Estimating the reproductive number and the outbreak size of COVID-19 in Korea. Epidemiol Health. 2020; 42:e2020011. https://doi.org/10.4178/epih.e2020011 PMID: 32164053

12. Ortelan N, Ferreira AJF, Leite L. et al. Cloth masks in public places: an essential intervention to prevent COVID-19 in Brazil. Cien Saude Colet. 2021; 26(2):669-92. https://doi.org/10.1590/141381232021262.36702020 PMID: 33605343

13. Ji D, Fan L, Li X, Ramakrishna S. Addressing the worldwide shortages of face masks. BMC Mater. 2020; 2(1):9. https://doi.org/10.1186/s42833-020-00015-w PMID: 32835173

14. Zhou SS, Lukula $S$, Chiossone $C$, et al. Assessment of a respiratory face mask for capturing air pollutants and pathogens including human influenza and rhinoviruses. J Thorac Dis. 2018; 10(3):2059-69. https://doi.org/10.21037/jtd.2018.03.103 PMID: 29707364

15. Offeddu V, Yung CF, Low MSF, Tam CC. Effectiveness of Masks and Respirators Against Respiratory Infections in Healthcare Workers: A Systematic Review and Meta-Analysis. Clin Infect Dis. 2017; 65 (11):1934-42. https://doi.org/10.1093/cid/cix681 PMID: 29140516

16. Chua MH, Cheng W, Goh SS, et al. Face Masks in the New COVID-19 Normal: Materials. Testing. and Perspectives. Re-search (Wash D C). 2020; 2020:7286735. https://doi.org/10.34133/2020/7286735 PMID: 32832908

17. Santos $\mathrm{M}$, Torres $\mathrm{D}$, Cardoso $\mathrm{PC}$, et al. Are cloth masks a substitute to medical masks in reducing transmission and contamination? A systematic review. Braz Oral Res. 2020; 34:e123. https://doi.org/10. 1590/1807-3107bor-2020.vol34.0123 PMID: 33146319

18. Silva ACOE, Almeida AM, Freire MEM, et al. Cloth masks as respiratory protections in the COVID-19 pandemic period: evidence gaps. Rev Bras Enferm. 2020; 73(suppl 2):e20200239. https://doi.org/10. 1590/0034-7167-2020-0239 PMID: 32965398

19. Sun P, Lu X, Xu C, et al. Understanding of COVID-19 based on current evidence. J Med Virol. 2020; 92 (6):548-51. https://doi.org/10.1002/jmv.25722 PMID: 32096567

20. Cowling BJ, Chan $\mathrm{KH}$, Fang VJ, et al. Facemasks and hand hygiene to prevent influenza transmission in households: a cluster randomized trial. Ann Intern Med. 2009; 151(7):437-46. https://doi.org/10. 7326/0003-4819-151-7-200910060-00142 PMID: 19652172

21. Cheng VC, Wong SC, Chuang VW, et al. The role of community-wide wearing of face mask for control of coronavirus disease 2019 (COVID-19) epidemic due to SARS-CoV-2. J Infect. 2020; 81(1):107-14 https://doi.org/10.1016/j.jinf.2020.04.024 PMID: 32335167

22. Kibuuka BGL. Complicity and Synergy Between Bolsonaro and Brazilian Evangelicals in COVID-19 Times: Adherence to Scientific Negationism for Political-Religious Reasons. International Journal of Latin American Religions. 2020; 4(2):288-317. https://doi.org/10.1007/s41603-020-00124-0

23. Massarani L, Neves LFF. Communicating the" race" for the COVID-19 vaccine: an exploratory study in newspapers in the United States. the United Kingdom and Brazil. 2021; 4:41. https://doi.org/10.3389/ fcomm.2021.643895

24. Brooks JT, Butler JC. Effectiveness of Mask Wearing to Control Community Spread of SARS-CoV-2. JAMA. 2021; 325(10):998-9. https://doi.org/10.1001/jama.2021.1505 PMID: 33566056

25. Centers for Disease Control and Prevention. CDC. 2021. Science Brief: Community Use of Cloth Masks to Control the Spread of SARS-CoV-2. https://www.cdc.gov/coronavirus/2019-ncov/science/ science-briefs/masking-science-sars-cov2.html. Accessed April 5. 2020.

26. Clapham HE, Cook AR. Face masks help control transmission of COVID-19. Lancet Digit Health. 2021; 3(3):e136-e7. https://doi.org/10.1016/S2589-7500(21)00003-0 PMID: 33483278

27. Mitze T, Kosfeld R, Rode J, Wälde K. Face masks considerably reduce COVID-19 cases in Germany. Proc Natl Acad Sci U S A. 2020; 117(51):32293-301. https://doi.org/10.1073/pnas.2015954117 PMID: 33273115

28. Chu DK, Akl EA, Duda S, et al. Physical distancing. face masks. and eye protection to prevent personto-person trans-mission of SARS-CoV-2 and COVID-19: a systematic review and meta-analysis. Lancet. 2020; 395(10242):1973-87. https://doi.org/10.1016/S0140-6736(20)31142-9 PMID: 32497510

29. Ma QX, Shan $\mathrm{H}$, Zhang HL, et al. Potential utilities of mask-wearing and instant hand hygiene for fighting SARS-CoV-2. J Med Virol. 2020; 92(9):1567-71. https://doi.org/10.1002/jmv.25805 PMID: 32232986

30. Morais FG, Sakano VK, Lima LN, Franco MA, et al. Filtration efficiency of a large set of COVID-19 face masks commonly used in Brazil. Aerosol Sci Technol. 2021; 55:9,1028-1041. https://doi.org/10.1080/ 02786826.2021.1915466 
31. Lindsley WG, Beezhold DH, Coyle J, et al. Efficacy of universal masking for source control and personal protection from simulated cough and exhaled aerosols in a room. J Occup Environ Hyg. 202118 (8):409-422. https://doi.org/10.1080/15459624.2021.1939879 PMID: 34161193

32. Williams CM, Decker JP, Wisniewska A, et al. Exhaled SARS-CoV-2 quantified by face-mask sampling in hospitalised patients with COVID-19. J Infect. 2021 Jun; 82(6):253-259. https://doi.org/10.1016/j.jinf. 2021.03.018 PMID: 33774019

33. Zangmeister CD, Radney JG, Vicenzi EP, Weaver JL. Filtration Efficiencies of Nanoscale Aerosol by Cloth Mask Materials Used to Slow the Spread of SARS-CoV-2. ACS Nano. 2020; 14(7):9188-9200. https://doi.org/10.1021/acsnano.0c05025 PMID: 32584542

34. Fernandes LAC, Silva CAF, Dameda C, Bicalho PPG. Covid-19 and the Brazilian Reality: The Role of Favelas in Combating the Pandemic. Front. Sociol. 2020; 5:611990. https://doi.org/10.3389/fsoc.2020. 611990 PMID: 33869528

35. United Nations. Brazil's favelas organize to fight Covid-19 2021. https://www.un.org/en/coronavirus/ brazil\%E2\%80\%99s-favelas-organize-fight-covid-19. Accessed April 9. 2020.

36. Pereira RJ, Nascimento GNLD, Gratão LHA, Pimenta RS. The risk of COVID-19 transmission in favelas and slums in Brazil. Public Health. 2020; 183:42-3. https://doi.org/10.1016/j.puhe.2020.04.042 PMID: 32422438

37. Griffith DM, Sharma G, Holliday CS, et al. Men and COVID-19: A Biopsychosocial Approach to Understanding Sex Dif-ferences in Mortality and Recommendations for Practice and Policy Interventions. Prev Chronic Dis. 2020; 17:E63. https://doi.org/10.5888/pcd17.200247 PMID: 32678061

38. Peckham H, de Gruijter NM, Raine $\mathrm{C}$, et al. Male sex identified by global COVID-19 meta-analysis as a risk factor for death and ITU admission. Nat Commun. 2020; 11(1):6317. https://doi.org/10.1038/ s41467-020-19741-6 PMID: 33298944

39. Bienvenu LA, Noonan J, Wang X, Peter K. Higher mortality of COVID-19 in males: sex differences in immune response and cardiovascular comorbidities. Cardiovasc Res. 2020; 116(14):2197-2206. https://doi.org/10.1093/cvr/cvaa284 PMID: 33063089

40. Huff HV, Singh A. Asymptomatic Transmission During the Coronavirus Disease 2019 Pandemic and Implications for Public Health Strategies. Clin Infect Dis. 2020; 71(10):2752-2756. https://doi.org/10. 1093/cid/ciaa654 PMID: 32463076

41. Zou L, Ruan F, Huang M, et al. SARS-CoV-2 Viral Load in Upper Respiratory Specimens of Infected Patients. N Engl J Med. 2020 Mar 19; 382(12):1177-1179. https://doi.org/10.1056/NEJMc2001737 PMID: 32074444

42. Dhama K, Khan S, Tiwari R, et al. Coronavirus Disease 2019-COVID-19. Clin Microbiol Rev. 2020; 33 (4): e00028-20. https://doi.org/10.1128/CMR.00028-20 PMID: 32580969

43. Buitrago-Garcia D, Egli-Gany D, Counotte MJ, et al. Occurrence and transmission potential of asymptomatic and pre-symptomatic SARS-CoV-2 infections: A living systematic review and meta-analysis. PLoS Med. 2020; 17(9): e1003346. Published 2020 Sep 22. https://doi.org/10.1371/journal.pmed. 1003346 PMID: 32960881 